\title{
Open valvotomy for critical aortic stenosis in infancy
}

M Burch, A N Redington, J S Carvalho, P Rusconi, E A Shinebourne, M L Rigby, $M$ Paneth, C Lincoln

\begin{abstract}
Over a 5 year period open valvotomy was performed on 13 patients under the age of one year with critical aortic stenosis. All 13 survived operation. There were two late deaths—one 38 days after operation, associated with an unrelated neurosurgical procedure and the other 2 years 6 months after when aortic root enlargement and replacement of the aortic valve were performed. During this period two other infants presented with aortic stenosis. One, who was very ill before transfer, died before operation could be performed. The second patient had a hypoplastic left ventricle with a small mitral valve ring and was, therefore, considered to be part of a different subgroup. All the surviving children have been followed up (median length of follow up 2 years and 11 months, range 7 months-5 years). Left ventricular function, in terms of percentage systolic wall thickening, was shown to be significantly impaired in all age groups. Peak diastolic thinning was abnormal in those children aged from 3 to 5 . The aortic valve gradient, as assessed by peak instantaneous continuous wave Doppler, was $<40 \mathrm{~mm} \mathrm{Hg}$ in five patients and between 40 and $70 \mathrm{~mm} \mathrm{Hg}$ in seven patients. One patient, with appreciable restenosis, has undergone successful percutaneous balloon dilatation of the aortic valve.
\end{abstract}

The mortality for aortic valvotomy in children over one year of age is low. ${ }^{2}$ In contrast, mortality is high in those below the age of one year. Various operative techniques have been used in infancy including circulatory arrest and hypothermia, ${ }^{3}$ inflow occlusion and partial cardiopulmonary bypass, ${ }^{4}$ inflow occlusion alone, ${ }^{5-7}$ cardiopulmonary bypass ${ }^{289}$ transventricular valvotomy with blunt dilatation, ${ }^{111}$ and transventricular balloon dilatation of the valve..$^{1213}$ The surgical mortality in these studies has varied from $9 \%$ to $66 \%$. Recently, small series treated by percutaneous balloon dilatation have been reported..$^{14-16}$ In the largest series published so far mortality was high ${ }^{17-19}$ and transverse tears of the aortic wall were reported with this technique..$^{20}$ Our preferred technique is open surgical valvotomy with conventional cardiopulmonary bypass. We report our results over a 5 year period.
Patients and methods

From September 1982 to September 1987, 13 patients presented with critical aortic stenosis. Their median age was 14 days (range 1-91) and the median weight was $4 \cdot 0 \mathrm{~kg}$ (range 2.2-6.4). Endocardial fibroelastosis was present in four patients. Three patients were pulseless and poorly perfused at presentation - one of them had an initial pH of 6.9 and the other two were resuscitated with immediate ventilation and intravenous bicarbonate before blood gases were measured. Seven patients presented with heart failure. Three were symptom free and the gradients from left ventricle to ascending aorta were therefore investigated. Two of these patients underwent preoperative cardiac catheterisation (no other patients were catheterised before operation); the third had ST segment depression on an electrocardiogram and the aortic valve gradient was assessed by continuous wave Doppler. The mean gradient of these three (left ventricle to aorta) was $120 \mathrm{~mm} \mathrm{Hg}$. None of the 13 patients had a hypoplastic left ventricle by echocardiographic criteria. ${ }^{221}$ Another two patients were excluded. One patient had disseminated intravascular coagulation, necrotising enterocolitis, and a pulmonary haemorrhage before transfer to our institution and died before operation could be performed. The other had a hypoplastic left ventricle. At echocardiography the diameter of the mitral valve was $<10 \mathrm{~mm}$ and the ventricle was spherical with a maximum transverse cavity dimension of $6 \mathrm{~mm}$. This is in keeping with previously described criteria for diagnosing a hypoplastic left ventricle. Although this patient underwent valvotomy he died after operation. He was considered to be part of a separate subgroup and to have died as a consequence of a small mitral valve annulus and a small left ventricle.

\section{METHODS}

All patients had an open aortic valvotomy. Conventional cardiopulmonary bypass with moderate hypothermia was used in 11 patients and inflow occlusion in two patients.

Eleven of the patients were studied with continuous wave Doppler (Doptech scanner), cross sectional echocardiography, and M mode echocardiography and the other patient was studied by Doppler flow at another hospital. Investigations were performed at a median of 2 years 11 months (range 7 months -5 years) after operation. Of the $11 \mathrm{M}$ mode echocardiograms, 10 were of sufficiently high quality to enable digitisation to be performed (fig 1) as 
previously described. ${ }^{22}$ Three beats were digitised from each patient. Left ventricular cavity dimensions and posterior wall thickness were measured throughout the cardiac cycle (fig 2). From these we obtained indices of systolic function (percentage systolic wall thickening, fractional left ventricular shortening $(\%)$, peak rate of systolic wall thickening $(\mathrm{cm} / \mathrm{s})$ and diastolic function (peak rate of diastolic wall thinning $\mathrm{cm} / \mathrm{s}$, and peak rate of left ventricular filling $\mathrm{cm} / \mathrm{s}$ ) (fig 3 ).

All data were expressed as mean (1 SD). Variables were compared by Student's $t$ test. The null hypothesis was rejected if $p<0.05$.

We compared results obtained with previously reported normal ranges for children aged 1-3 and 3-5 years from our hospital. ${ }^{23}$

\section{Results}

There was no operative mortality. One patient died 38 days after operation during an unrelated neurosurgical procedure. The mean peak instantaneous gradient at recent continuous wave Doppler was $41 \mathrm{~mm} \mathrm{Hg}$ (range 8$70 \mathrm{~mm} \mathrm{Hg}$ ). A gradient of between 40 and $70 \mathrm{~mm} \mathrm{Hg}$ was found in seven patients (fig 4) and one has recently undergone successful percutaneous balloon dilatation of the aortic valve. There was no relation between age and Doppler gradient. Two patients had significant aortic incompetence clinically and echocardiographically; recently one of them underwent aortic root enlargement and aortic valve replacement (19 $\mathrm{mm} \mathrm{St} \mathrm{Jude} \mathrm{prosthesis)} 2$ years and 6 months after her initial operation. At operation the valve was found to be bicuspid and the original incision that had been taken to one side of the anterior commissure was believed to be causing the incompetence. The postoperative course was complicated by poor ventricular function and recurrent ventricular tachycardia and the patient died on the 23rd postoperative day.

The table shows indices of systolic and diastolic function obtained from the $M$ mode echocardiograms. The mean heart rates were 117 (19) (1-3 years) and 99 (24) (3 to 5 years)

Figure $1 \quad M$ mode echocardiogram of the left ventricle at the level of the mitral valve from a 3 year old patient with previous critical aortic stenosis. ECG, electrocardiogram; phono, phonocardiogram, IVS, intraventricular septum; $L V P W$, left ventricular posterior wall.
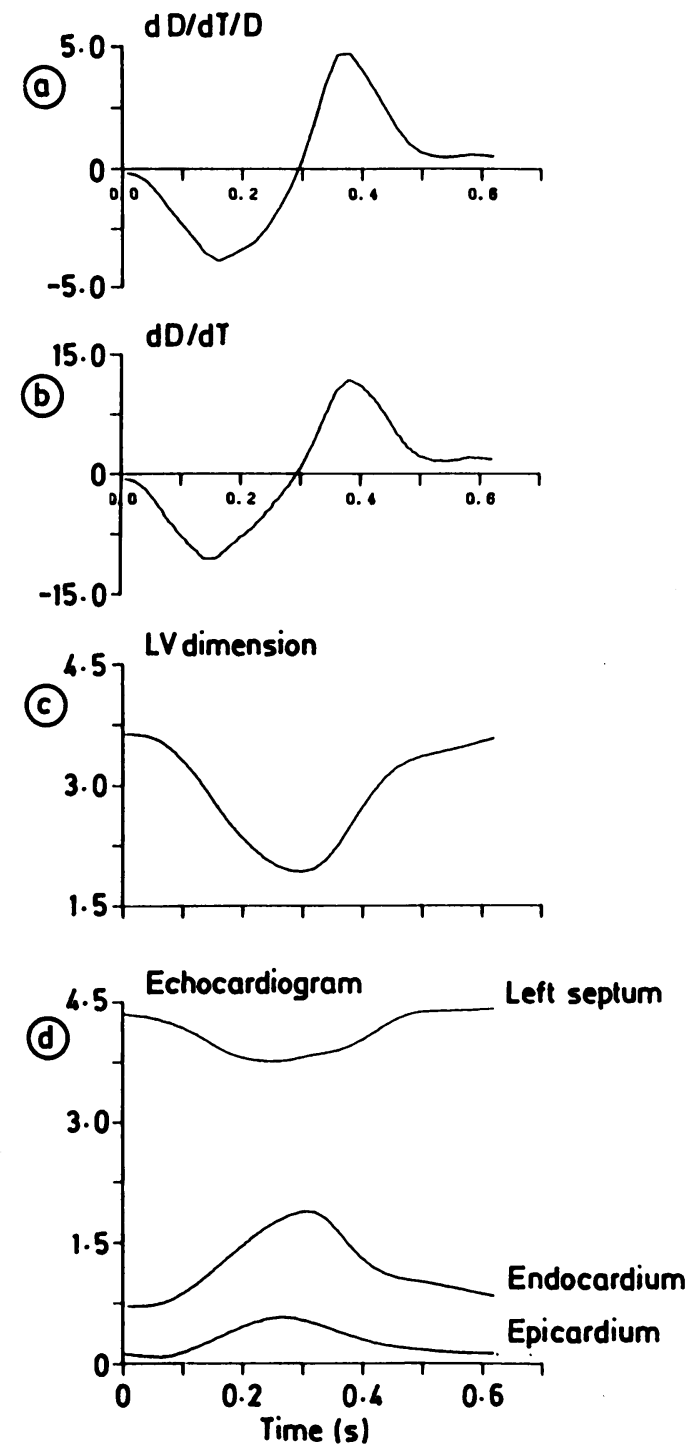

Figure 2 Computer output of digitised echocardiogram: (a) normalised rate of change of dimension $(d D / d t / D)$ (per s); (b) rate of change of left ventricular dimension $(\mathrm{d} D / d \mathrm{t})(\mathrm{cm} / \mathrm{s}) ;(\mathrm{c})$ instantaneous change in left ventricular $(L V)$ dimension $(D)(\mathrm{cm}) ;(d)$ digitised $M$ mode echocardiogram $(\mathrm{cm})$.

per minute, which resemble normal rates. ${ }^{21}$ There was significant reduction in the value of percentage systolic wall thickening $(p<0.001)$ in children in both age groups $(1.5-3$ years and 3-5 years). Peak diastolic thinning was decreased in the group aged 3-5 years $(p<$ 0.02 ). Other values were not significantly abnormal. There was only one patient under 1.5 years of age and, although digitisation was performed, there are no normal data with which to compare the results in this patient. However, if the values are compared with the 1.5-3 year group then peak left ventricular filling and percentage systolic wall thickening were significantly decreased $(p<0.001)$ as were peak diastolic thinning and fractional left ventricular shortening $(p<0.01)$. In the child who died after aortic root enlargement and aortic valve replacement percentage wall thickening (34.6\%) was decreased and fractional left ventricular shortening $(20.5 \%)$ was considerably reduced.

\section{Discussion}

Our study showed that during the 5 year period 
Figure 3 Computer output of digitised echocardiogram: (a) normalised rate of change of left ventricular posterior wall thickness; (b) instantaneous rate of change of left ventricular posterior wall thickness; posterior wall thickness; thickness measured continuously.
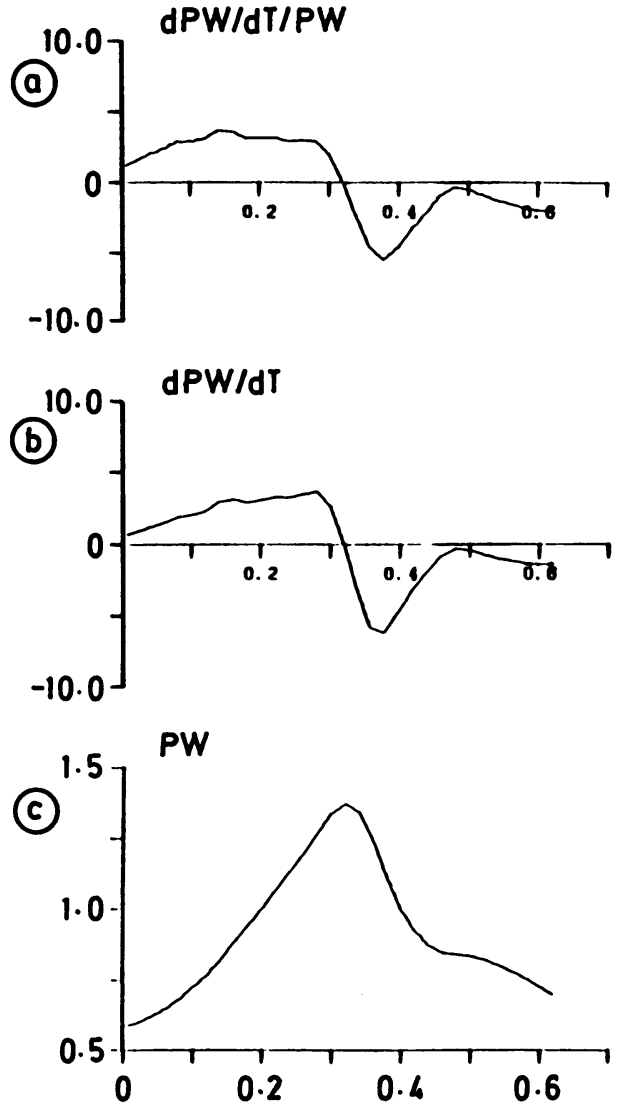

from September 1982 to September 1987 open aortic valvotomy for critical aortic stenosis in infancy was not associated with any early ( 30 day) mortality. However, we excluded a patient who retrospectively we considered to have a hypoplastic left ventricle by established echocardiographic criteria ${ }^{21}$ and who died in the postoperative period. We view patients with hypoplastic left ventricle as a subgroup in which others have shown a $100 \%$ mortality for aortic valvotomy. ${ }^{24} 25$ Our current practice is to consider these patients for a Norwood procedure. ${ }^{26}$ If, where possible, the deaths of patients with hypoplastic left ventricle are excluded from the series of patients undergoing balloon dilatation of the aortic valve, then the early mortality is $54 \%$ and $100 \%$ respectively ${ }^{1719}$; however, in another study early mortality was only $19 \%$ for all patients. ${ }^{18}$

Our retrospective study highlights the need for careful follow up. Although all the survivors are well, seven patients had a gradient of between $40 \mathrm{~mm} \mathrm{Hg}$ and $70 \mathrm{~mm} \mathrm{Hg}$ on continuous wave Doppler. Two patients had considerable aortic incompetence. One patient died after enlargement of the aortic root and replacement of the aortic valve. To date, none of our other patients has required reoperation, but one has undergone percutaneous balloon dilatation of the aortic valve. It is likely that

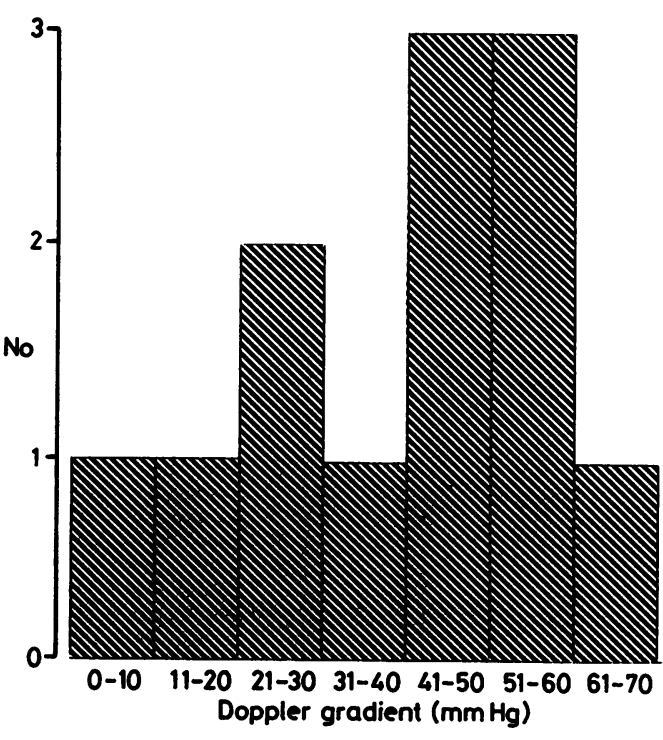

Figure 4 Distribution of peak instantaneous gradients from the left ventricle to the aorta as measured by continuous wave Doppler.

others will need further relief of aortic stenosis in the near future.

Left ventricular function (in terms of percentage systolic wall thickening) was abnormal in children aged 1.5-3 years and those aged 3-5 years. In addition, diastolic function (in terms of peak diastolic thinning) was significantly decreased in the group aged 3-5 years. This may reflect the increase in fibrous tissue in the left ventricle that has been described in adults with aortic stenosis. ${ }^{27}$ Other indices were reassuringly normal. Longer term follow up will be required to assess the clinical implications of these abnormalities of systolic and diastolic function.

Recently a mortality of $15 \%$ for open aortic valvotomy in infants over a 13 year period with no deaths since 1979 has been reported. ${ }^{28}$ However, the patients were slightly older at presentation than the ones we described (median age 8 weeks as opposed to 2 weeks). Allied with the low mortality for open valvotomy at our hospital, this produces a firm background of contemporary data against which other procedures should be judged. At present we hesitate to adopt a policy of primary percutaneous balloon dilatation of the aortic valve in infancy. The mean Doppler gradient across the aortic valve at follow up in the recent series $^{28}$ was similar to the one that we report (mean $43 \mathrm{~mm} \mathrm{Hg}$ compared with $41 \mathrm{~mm} \mathrm{Hg}$ ) but we found fewer patients with aortic regurgitation. It seems likely, therefore, that intervention will be necessary in several patients in the future. At repeat valvotomy the valve cusps have been described as flexible and non-calcified in most, suggesting maturation of

Left ventricular ( $L V)$ systolic and diastolic function at follow up (mean (1 SD))

\begin{tabular}{|c|c|c|c|c|c|}
\hline Age (yr) & $\begin{array}{l}\text { Peak rate of diastolic } \\
\text { thinning }(\mathrm{cm} / \mathrm{s})\end{array}$ & $\begin{array}{l}\text { Peak rate of } L V \\
\text { filling }(\mathrm{cm} / \mathrm{s})\end{array}$ & $\begin{array}{l}\text { Systolic wall } \\
\text { thickening }(\%)\end{array}$ & $\begin{array}{l}\text { Fractional } L V \\
\text { shortening }(\%)\end{array}$ & $\begin{array}{l}\text { Peak rate of systolic } \\
\text { wall thickening }(\mathrm{cm} / \mathrm{s})\end{array}$ \\
\hline $\begin{array}{l}<1.5(n=1) \\
1 \cdot 5-3(n=5) \\
\text { Normal range } \\
3-5(n=5) \\
\text { Normal range }\end{array}$ & $\begin{array}{l}3 \cdot 0(0 \cdot 1) \\
3.9(1 \cdot 24) \\
(5.0(1 \cdot 4)) \\
4 \cdot 37(2 \cdot 12) \\
(8.6(2 \cdot 0))\end{array}$ & $\begin{array}{c}5.3(0 \cdot 1) \\
9.64(1 \cdot 83) \\
(9 \cdot 2(1 \cdot 3)) \\
10 \cdot 17(4 \cdot 15) \\
(11.2(3.7))\end{array}$ & $\begin{array}{l}23.4(3.1) \\
38 \cdot 40(10 \cdot 30) \\
(113(24)) \\
36.37(14 \cdot 18) \\
(107(39))\end{array}$ & $\begin{array}{l}21.7(3.1) \\
31.9(6 \cdot 7) \\
(32(7)) \\
39.5(8 \cdot 2) \\
(34(3))\end{array}$ & $\begin{array}{l}2.5(0.7) \\
2.76(0.81) \\
(2.9(1.0)) \\
2.92(0.88) \\
(3.2(1.2))\end{array}$ \\
\hline
\end{tabular}


the original embryonal structure. ${ }^{6}$ We have, therefore, performed percutaneous balloon dilatation of the aortic valve when repeat valvotomy has been required.

We thank Dr D Gibson for his advice.

1 Mackworth-Young CG, Dawkins KD, Kay PH, Paneth M Aortic valvotomy in the treatment of congenital aortic Aortic valvotomy in the treatment of congenital a
stenosis. J Cardiovasc Surg (Torino) 1985;26:433-8.

2 Tveter KJ, Foker JE, Moller JH, Ring WS, Lillehei CW, Varco RL. Long term evaluation of aortic valvotomy fo congenital aortic stenosis. Ann Surg 1987;206:496-503.

3 Chiariello L, Agosti J, Vlad P, Subramanian J. Congenital aortic stenosis, experience with 43 patients. $J$ Thorac Cardiovasc Surg 1976;72:182-93.

4 Cooley DA, Beall AC, Hallman GL, Bricker DL. Obstructive lesions of the left ventricular outflow tract. Circulation 1965;32:612-21.

5 Sink JD, Smallhorn JF, Macartney FJ, Taylor JFN, Stark J, de Leval MR. Management of critical aortic stenosis in infancy. $J$ Thorac Cardiovasc Surg 1984;87:82-6.

6 Keane JF, Bernhard WF, Nadas AS. Aortic stenosis surgery in infants. Circulation 1975;52:1138-43.

7 Pelech AN, Dyck JD, Trusler GA, et al. Critical aortic stenosis, survival and management. $J$ Thorac Cardiovasc Surg 1987;94:510-7.

8 Wheller JJ, Hosser DM, Teske DW, Craenen JM, Kilman JW. Results of operation for aortic valve stenosis in infants, children and adolescents. $J$ Thorac Cardiovasc infants, children and
Surg 1988;96:474-7.

9 Messina CM, Turley K, Stanger P, Hoffman JE, Ebert PA. Successful aortic valvotomy for congenital valvular aortic stenosis in the newborn infant. $J$ Thorac Cardiovasc Surg 1984;88:92-6.

10 Trinkle JK, Norton JB, Richardson JD, Grover FL, Noonan JA. Closed aortic valvotomy and simultaneous correction of associated anomalies in infants. $J$ Thorac Cardiovasc Surg 1975;69:758-62.

11 Duncan K, Sullivan I, Robinson P, Horvath P, de Leval M Stark J. Transventricular aortic valvotomy for critica aortic stenosis in infants. J Thorac Cardiovasc Surg 1987;93:546-58.

12 Brown JW, Robinson RJ, Waller BF. Transventricular balloon catheter aortic valvotomy in neonates. Ann Thorac Surg 1985;39:376-8.
13 Phillips RR, Gerlis LM, Wilson N, Walker DR. Aortic valve damage caused by operative balloon dilatation of critical aortic valve stenosis. Br Heart J 1987;57:168-70.

14 Sanchez GR, Ashok VH, Ewing LL, Brickley SE, Anderson TM, Black IFS. Successful percutaneous balloon valvuloplasty of the aortic valve in an infant. Pediatr Cardiol 1985;6:103-5.

15 Rupprath G, Neuhaus KL. Percutaneous balloon valvuloplasty for aortic valve stenosis in infancy. $\mathrm{J} \mathrm{Am} \mathrm{Coll}$ plasty for aortic valve

16 Lababidi $Z$, Weinhaus L. Successful balloon valvuloplasty for neonatal critical aortic stenosis. Am Heart J 1986;112:913-7.

17 Wren C, Sullivan I, Bull C, Deanfield J. Percutaneous balloon dilatation of aortic valve stenosis in neonates and infants. Br Heart J 1987:58:608-12.

18 Zeevi B, Keane JF, Castaneda AR, Perry SB, Lock JE. Neonatal critical aortic stenosis: surgery vs balloon dilatation [Abstract]. Circulation 1988;78 (suppl II): 1956

19 Ladusans EJ, Parsons JM, Qureshi SA, Baker EJ, Tynan MJ. Results of percutaneous balloon dilatation for critical aortic stenosis in neonates with severe endocardial fibroelastosis [Abstract]. Br Heart $J$ 1989;61:470.

20 Waller BF, Girod DA, Dillon JC. Transvere aortic wall tears in infants after balloon angioplasty for aortic valve stenosis. J Am Coll Cardiol 1984;4:1235-41.

21 Latson LA, Cheatham JP, Gutgesell HP. Relation of the echocardiographic estimate of left ventricular size to mortality in infants with severe left ventricular outflow obstruction. Am J Cardiol 1981;48:887-91.

22 Gibson DG, Brown DJ. Measurement of instantaneous left ventricular dimension and filling rate in man, using ventricular dimension and filling rate in man, using

23 St John Sutton MG, Marier DL, Oldershaw PJ, Sacchetti R, Gibson DG. Effect of age related charges in chamber size, wall thickness, and heart rate on left ventricular function wall thickness, and heart rate on left ventricular

24 Keane JF, Norwood WI, Bernhard WF. Surgery for aortic Keane JF, Norwood WI, Bernhard WF. Surgery for aortic
stenosis in infancy [Abstract]. Circulation 1983;68 (suppl II): 182

25 Hammon JW, Lupinetti FM, Maples MD, et al. Predictors of operative mortality on critical valvular aortic stenosis presenting in infancy. Ann Thorac Surg 1988;45:537-40.

26 Norwood WI, Lang P, Hansen DP. Physiologic repair of aortic atresia-hypoplastic left heart syndrome. $N$ Engl $J$ Med 1983;308:23-6.

27 Oldershaw PJ, Brooksby IAB, Davies MJ, Coltart DJ, Jenkins BS, Webb-Peploe MM. Correlations of fibrosis in endomyocardial biopsies from patients with aortic valve disease. Br Heart J 1980;44:609-11.

28 Balaji S, Keeton BR, Sutherland GR, Shore DF, Monro JL. Aortic valvotomy for critical aortic stenosis in neonates and infants aged less than one year. Br Heart J 1989;61:358-60 